\title{
The Life and Growth of Year 12 Computing in Victoria: An Ecological Model
}

\author{
Arthur Tatnall $^{1}$ and Bill Davey ${ }^{2}$ \\ ${ }^{1}$ Graduate School of Business, Victoria University, Australia \\ Arthur. Tatnallevu.edu.au \\ ${ }^{2}$ School of Business Information Technology, RMIT University, Australia \\ Bill.Davey@rmit.edu.au
}

\begin{abstract}
This paper seeks to apply the techniques of ecology, used in a wide range of fields, to analyse a series of events in the history of computing. The case analysed here is the history of development of computer studies curriculum at the senior level in high schools in the Australian state of Victoria. Although theoretically directed by a central body, development of the curriculum for the final high school year in computing shows a history containing many anomalies. Applying an ecological method to the historical narrative shows that seemingly illogical changes can be explained by the interaction of organisms and the environment in which the history has taken place. From this example we will show that ecological principles can also be useful in analysing an historical event.
\end{abstract}

Keywords: Computer Science, Information Technology, computer studies curriculum, history, senior secondary school curriculum, ecological methods.

\section{Introduction}

In many school systems the 'worth' of a subject is measured in terms of its interaction with the final year of schooling (Year 12) as many ascribe special importance to those subjects that are seen as valid preparations for tertiary study. In 1981, as a result of many years of effort by a group of academics, Computer Science was first offered as a Higher School Certificate (Year 12) subject in the Australian state of Victoria [1].

Until the 1960s the final year of high school in Victoria had been known as Matriculation. This word, meaning qualification to enter the University, illustrates the way in which the final year of high school was seen as a preparation for university studies, and all subjects were closely aligned to a similar study at university. In the 1960s in a review of the senior secondary school system the Higher School Certificate (HSC) was introduced in place of the Matriculation certificate. Another review of upper secondary school curriculum in the early 1990s replaced the Higher School Certificate by the Victorian Certificate of Education (VCE) that extended over Years 11 and 12.

Introduction of the VCE brought with it a number of changes to existing subjects, and saw Computer Science replaced with three new Year 12 subjects: Information Processing and Management, Information Systems and Information Technology in Society. Each of these subjects comprised two units. An additional new subject: Information Technology was offered only at Year 11. 


\section{An Historical Approach}

Some writings in the history of computing have sought to record, in an uncensored narrative, the stories of the pioneers of computing (before we lose them). On the other hand there is also an opportunity for articles to analyse the history presented in these narratives and seek to learn from the trends that are uncovered. George Santayana is often quoted as saying "If we do not learn from the mistakes of history, we are doomed to repeat them." His philosophy text [2] actually said "Those who cannot remember the past are condemned to repeat it", but in either case it is the analysis and historical record that allow us to avoid condemnation, or the repetition of mistakes.

Historical record is a complex field and in the analysis of complex fields a number of techniques have been developed to avoid the perils of reductionism. Often in applying scientific method to complex situations we can remove meaning at the same time that we remove complexity. In this paper we will take a particular piece of the history of computing and apply an ecological method to draw out the meaning contained in the history.

The science of Ecology has developed many different ways of investigating nature. Ecology is concerned with interrelationships between different living things, and between living things and their environment [3]. In addition to dealing with the natural environment however, the principles of Ecology have been used in many other areas to deal with the complexity of those areas [4-13]. These techniques have also been used in education and curriculum development to produce worthwhile results [3, 14-19]

\subsection{Anomalies in the Historical Case}

In this paper we use as the unit of analysis, the history of the development of computing studies curricula in high schools in Victoria. In Victoria the senior secondary school curriculum is controlled by a central body that has had a number of names during the history we are recording, but is currently called the Victorian Curriculum and Assessment Authority. This authority attempts to respond to the needs of the community to produce new HSC subjects as the need arises. These subjects are reviewed on a regular basis and changes are made in response to industry, community and university suggestions. University entrance in Australia is highly competitive and determined almost completely by the results obtained by the student in their final year of high school. There are state-wide and nationally moderated assessments of all final high school subjects to determine a score (called the ENTER score) used by most universities for entrance requirements. This means that the authority must make changes to the curriculum carefully in logical response to real needs.

Despite this central control, the intense pressure to make sure that all subjects offered meet the needs of society and students, and attempts to make only rational decisions in terms of this curriculum, the history of the development of computing curriculum is filled with anomalous outcomes. These include:

- One subject introduced in order to make computing accessible and popular has been abandoned due to low enrolments. 
- Changes to other subjects intended to make them more popular with girls have seen little in the way of improving the long-term gender balance.

\section{Elements of the Ecological Method}

Townsend, Harper and Begon [20] suggest that two key biological principles exemplify the concepts of ecology:

- Organisms behave in ways that optimise the balance between their energy expenditure and the satisfaction they obtain.

- Organisms operate within a competitive environment that ensures only the most efficient of them will survive [3].

Using the principles of ecology to analyse complex situations means more than just trying to find a correspondence or a metaphor between the situation and the ecological entity. In ecology it has been found useful to make distinctions between organisms, resources and the environment in which these organisms must prosper or die, and there are simple principles that underlie the success or failure of organisms within an environment. Habitat, ecological niches, the exploitation of resources in predator-prey interactions, competition, and multi-species communities [21, 22] are all important considerations in ecology [3]. These principles, however, are also found to be useful in analysing other complex situations that do not necessarily involve biological entities. The first step in an ecological analysis requires us to identify several different entities:

- Those things that cannot be changed by the organisms (actors) we will call the environment.

- Those things that are consumed by the organisms but are unable to influence these organisms, except by their consumption, we will call resources.

- Those things that are able to consume resources and interact with each other, and which may prosper or die over time we will call the organisms.

When seeking to explain the success or failure of an organism we will look for interactions between the organism, its environment and the resources available. There are several principles found in biologically ecologies that are common to other complex situations:

- Organisms can prosper if they find a niche in the environment that particularly suits them.

- Organisms prosper when they use the least energy to obtain the greatest response.

- Organisms can prosper by being cooperative with other organisms in the environment.

- Organisms can prosper through competitive behaviour with other organisms and environments.

An ecosystem is a highly complex entity due to the large number of living things inhabiting it, and to the variety of interactions possible between each of these [15]. We will look for these ecological principles within the history of our case. 


\section{Analysing This Case Using the Ecological Model}

In this case the environment includes: University entrance places - these are a rare and difficult location to reach in the environment, Government policy and public perceptions. Environmental resources include: student enrolments - these are attracted by the different subjects that make up the final year of high school. A subject that is able to attract a large number of students will be successful, while one unable to attract students will die.

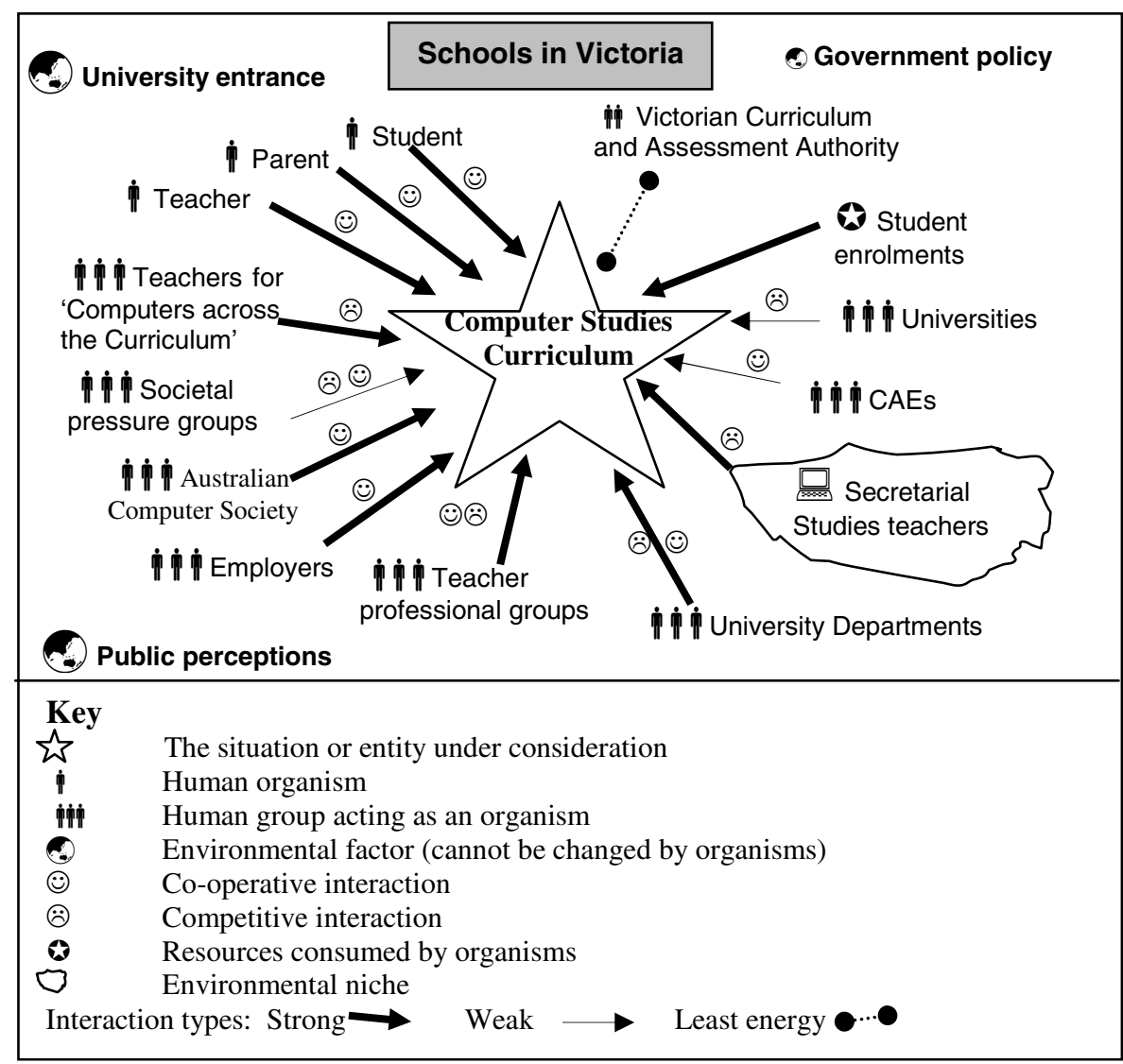

Fig. 1. TD diagram of the interactions in the ecological model

Organisms include: the subjects - these are non-biological organisms, students, teachers, universities, industry, employers, the Australian Computer Society (ACS), pressure groups and the general public. University departments seek to support subjects that they see as co-operating with them. Teachers represented through their professional groups seek to make changes in subjects - subject-based teacher groups support their own subjects. 
We will now look at the way the history of this development unfolds from the point of view of the ecological model.

\subsection{Turning Points and Ecological Explanations}

\subsubsection{The First Turning Point We Examine Is the Birth of a New Organism}

In the Victorian education system, as in many education systems around the world, senior high school studies have closely reflected the major disciplines in universities. When the HSC subject Computer Science was first introduced in 1981, however, it was done without the existence of many corresponding subjects in Australian universities.

Our ecological model asks us to look at the relationships of this new subject to the other organisms and to the environment: tertiary institutions, schools, teacher groups and the general public. Most of the pressure to introduce this subject came from outside the Education Department, and secondary school teachers had little involvement in determining its nature or content.

The public: parents, students and employers; readily accepted HSC Computer Science, and student numbers taking the new subject increased rapidly. In its first year, 120 students from 10 schools studied Computer Science, but this number increased by over $50 \%$ in each of the next five years before making a slower increase to over 2200 in 1991 (only a little smaller than Geography) with virtually every secondary school in the state offering the subject. [23]

Melbourne and Monash universities, which saw themselves as guardians of academic standards, initially rejected the subject, not allowing its inclusion in admission scores for their courses. Their stated reason for this was that the component of assessment allotted to the formal examination was only $35 \%$ in HSC Computer Science rather than the usual $50 \%$. (The subject designers had allotted only $35 \%$ to the formal examination to allow space for practical work in programming to be given some weight.) When pressed, several academics from these institutions admitted that they considered the subject of little serious academic worth, and 'not an appropriate subject to study at a secondary school level' [1]. They would often state that they would prefer to have a student with no knowledge of computing who they could introduce to computing concepts, rather than one 'who had learned bad programming in BASIC'. The fact that the Computer Science subject had been specifically constructed to address this particular concern by the study of top-down design and structured programming missed their notice.

Parallels can be drawn between the introduction of Computer Science and that of Geography in English schools as described by Goodson [1, 24]. In his analysis, Goodson makes use of Layton's [25] three stage model of the growth of science education in nineteenth century England.

1. Layton suggested that in the First Stage, a new subject stakes its place based on grounds of pertinence, utility and the needs and interests of the learners. In this stage learners are attracted as the subject relates to matters that concern them. Teachers tend not to be trained specialists, but pioneers who bring missionary zeal to their task. 
2. In the Second Stage a tradition of scholarly work begins to emerge and more teachers are recruited as trained specialists. Students are now increasingly attracted by the new subject's reputation and growing academic status. Subject matter in the new subject is becoming increasingly well organised.

3. In the Third and final stage the teachers have constituted a professional body with established rules and values. Subject matter is largely determined by specialist scholars in the field and students are thus initiated into a tradition.

An interesting variation is the reaction to the subject by tertiary institutions in Victoria. Several of the 'traditional' universities, which had been offering a highly abstract version of Computer Science for some time opposed introduction of the new subject at secondary school level, claiming that the concepts required of this discipline were beyond what could be understood by 17 year old students. On the other hand many of the newer tertiary institutions, then known as Colleges of Advanced Education (later to become universities), were generally quite supportive after fighting their own battles with the universities on the place of computing some years earlier. This partnership can be seen as a co-operation between the organism represented by the new subject and the organism represented by these new tertiary institutions.

Parents, students and employers readily accepted HSC Computer Science, and student numbers taking the new subject increased rapidly. Teachers, however, were not universally in favour. Beginning from about the mid-1980s when Computer Science was still in rapid growth a number of teachers began to question its place [1]. Their argument had several strands. Firstly, some claimed that HSC Computer Science was an elitist academic subject, too difficult for some students, and so should not be supported (- it is interesting to note that this was exactly opposite to the view earlier expressed by Melbourne and Monash universities). Others noted that the ratio of girls to boys taking Computer Science was almost as low as that for physics, and expressed concern that it was becoming a boy's subject. Perhaps, however, the most damaging criticism came from those teachers who claimed that the presence of a specialist subject detracted from the move to encourage the use of 'Computers across the Curriculum'. Their argument had two parts: firstly, they argued that the demands made on school computing facilities by Computer Science classes made it difficult for others to obtain adequate access to the machines. While containing some truth, this argument misses the point that in most cases the reason that the school had purchased a number of computers at all was to support the teaching of Computer Science. Secondly, it was argued that the existence of a specialist subject would mean that teachers of other subject areas would not bother to include any mention of computing, considering it covered elsewhere. A number of teachers saw Computer Science and Computers across the Curriculum as adversaries and it took some time before these competing points of view were reconciled [1].

\subsubsection{The Second Turning Point: Three New Subjects}

Changes to the structure of the Year 12 curriculum in the early 1990s resulted in the introduction of three new Information Technology subjects: Information Systems, Information Processing and Management and Information Technology in Society to replace Computer Science. This process also resulted in a decrease in any links between secondary curriculum and the universities. At this time several other subjects 
were made redundant as they were seen as having 'died' due to a perceived lack of interest. A subject of particular significance here was Secretarial Studies which had occupied a comfortable niche as a vocational subject preparing (mostly) girls for entry into office and administrative jobs. The idea of teaching typing on typewriters was, however, seen as anachronistic. The numerically large and influential group of teachers made redundant in this process produced a pressure group. These teachers had been moving slightly in their niche towards the use of electronic typewriters. This pool of teachers threatened with significant changes to their work on the demise of their own teaching subject can be seen as a powerful predator. When Secretarial Studies teachers were forced to move into computing, some attempted just to move their previous niche into a new location by ignoring, or de-emphasising, any content material that did not suit them. This aspect of their move into teaching Information Technology subjects can still be seen in the nature and scope of computing studies in the final school year.

Another predator within the environment was a group of teachers with a philosophical view that computers should be a tool used in every part of the curriculum rather than a topic to be studied by in its own right. After their success in killing off Computer Science, this 'Computers across the Curriculum' group continued to influence the way computers were used in secondary schools; an interesting example being that of mathematics. In mathematics every year level was now required to add computer-based learning of some kind into the curriculum. In 1999 it was found that computing resources in schools were not up to this demand, and a trial of using computers in the examination system failed. Mathematics teachers found the solution to this problem in using relatively inexpensive graphics calculators rather than computers, and use of Excel and Mathematica in schools decreased to almost zero.

\subsubsection{The Third Turning Point: Death of One of the New Subjects}

Another anomalous thing that happened was the downward progress of the subject: Information Technology in Society. By 1997 the numbers in this subject had become so low that it was not re-accredited for the next year. This is seen as an anomaly as the creation of the new courses in information technology was based on a few simple, logical propositions.

Information Technology was seen as having three main areas of interest:

1. Studying information technology itself - including programming

2. Studying the uses of information technology - especially in business

3. Studying the wider impact of information technology across the whole social landscape.

The idea of three streams was to cater to a wide audience. It was presumed that students fell into interest groups including those interested in technology and those interested in the social sciences. To have one of these streams collapse in such a short period of time showed that this model of students logically following some stereotyped interest is not valid.

In ecological terms we find a number of principles in action in this turning point. The creation of the stream is an example of the least energy relationship between the curriculum authority and subject offerings. A subject was proposed by the subcommittee handling computer related subjects and the option with the greatest return 
on energy expenditure for the authority was to offer the subject and see if it captured sufficient student numbers to survive. The subject had little chance to succeed in this environment as there was a co-operative relationship between university departments and both the other streams, but no interest from any department in the IT and Society subject. Similarly the industry groups anxious to increase the number of available employees in computing had no interest in co-operating with a subject that covered the potential evils of technology without developing many job related skills.

\subsubsection{The Fourth Turning Point: Failure of the New Subjects to Attract Girls}

One of the principal tenets for creation of the change from Computer Science to the three new streams of computing (Information Systems, Information Processing and Management and Information Technology in Society) was the desire to make the subjects more interesting and attractive to girls. By 2008, however, we find the gender balance in the two remaining subjects (Information Systems, Information Processing and Management) to have dropped to less than $25 \%$ girls. Clearly the intention to make these subjects amenable to girls has not been achieved and we need to look into the history of computing subjects to try to find out why.

The ecological approach is required to understand this continued failure, despite deliberate and conscious efforts to change subjects to include material of interest to girls. In this case the important issue is competitors in the form of other HSC subjects. The enrolment of females in the final year of high school and in subsequent university places increased over this period. These student enrolment resources were typically being taken up by 'traditional' female subjects such as those in commercial streams including legal studies, accounting and such, but were also being increasingly captured by biology and even mathematics. The commerce subjects can be seen as an example of least energy expenditure: a female student choosing a subject because she can 'end up doing the same things that mother did'. The movement towards biology and mathematics appears to be related to the large efforts in marketing by the feminist lobbies in society. These teacher and university department based groups were able to see a co-operative relationship between their aims and the identified subjects. This cooperative relationship was, however, never developed with any of the information technology subjects.

\section{Conclusion}

A naïve view of curriculum development sees central organisations making changes to curriculum in high schools in logical response to the needs of industry and society. The most cursory examination of any example of the history of computing in schools, however, shows numerous examples of changes that are neither logical nor related to changes in industry or society. Often central bodies are required to cancel subjects because of the lack of student numbers. We have shown here, using a particular case, that the history of computing in schools can be understood more clearly by using an ecological model based on the organisms, resources and the environment and looking at their interactions in terms of niches, expenditure of the least energy, cooperative and competitive behaviour. 


\section{References}

1. Tatnall, A.: The Growth of Educational Computing in Australia. In: Goodson, I.F., Mangan, J.M. (eds.) History, Context, and Qualitative Methods in the Study of Education, pp. 207-248. University of Western Ontario, Canada (1992)

2. Santayana, G.: The Life of Reason, vol. 1. C. Scribner's Sons (1905)

3. Tatnall, A., Davey, B.: Improving the Chances of Getting your IT Curriculum Innovation Successfully Adopted by the Application of an Ecological Approach to Innovation. Informing Science 7(1), 87-103 (2004)

4. Star, S.L., Griessemer, J.R.: Institutional Ecology, 'Translations' and Boundary Objects: Amateurs and Professionals in Berkley's Museum of Vertebrate Zoology, 1907-39. Social Studies of Science 19, 387-420 (1989)

5. Grzywacz, J.G., Fuqua, J.: The Social Ecology of Health: Leverage Points and Linkages. Behavioral Medicine 26(3), 101-115 (2000)

6. Barnett, W.P., Mischke, G.A., Ocasio, W.: The Evolution of Collective Strategies among Organizations. Organization Studies 21(2), 325-354 (2000)

7. Simon, D.: Ecological Metaphors of Security: World Politics in the Biosphere. Alternatives: Social Transformation \& Humane Governance 23(3), 291-320 (1998)

8. Sutcliffe, A., Chang, W.-C., Neville, R.: Evolutionary Requirements Analysis. In: 11th IEEE International Requirements Engineering Conference (RE 2003). IEEE, Monterey Bay (2003)

9. Podolny, J.M., Stuart, T.E.: A Role-Based Ecology of Technological Change. American Journal of Sociology 100, 1224-1260 (1995)

10. Havelka, D., et al.: Evolution of IS Professionals' Competency: an Exploratory Study. Journal of Computer Information Systems 41(4), 21 (2001)

11. Johnston, R.: Panel: Evolution of Computing in Spanish Speaking Countries (IFIP WCC 2006). IFIP, Santiago (2006)

12. Nagarajan, A., Mitchell, W.: Evolutionary Diffusion: Internal and External Methods Used to Acquire Encompassing, Complementary, and Incremental Technological Changes in the Lithotripsy Industry. Strategic Management Journal 10(11) (1998)

13. Richards, R.M., Sanford, C.C.: An Evolutionary Change in the Information Systems Curriculum at the University of North Texas. Computers and Education 19(3), 219-228 (1992)

14. Tatnall, A., Davey, B.: Curriculum Development in the Informing Sciences: Ecological Metaphor, Negotiation or Actor-Network? In: Informing Science and IT Education Conference. University College Cork, Cork (2002)

15. Tatnall, A., Davey, B.: Information Systems Curriculum Development as an Ecological Process. In: Cohen, E. (ed.) IT Education: Challenges for the 21st Century, pp. 206-221. Idea Group Publishing, Hershey (2002)

16. Tatnall, A., Davey, B.: Understanding the Process of Information Systems and ICT Curriculum Development: Three Models. In: Brunnstein, K., Berleur, J. (eds.) Human Choice and Computers: Issues of Choice and Quality of Life in the Information Society, pp. 275-282. Kluwer Academic Publishers/IFIP, Assinippi Park (2002)

17. Tatnall, A., Davey, B.: ICT and Training: A Proposal for an Ecological Model of Innovation. Educational Technology \& Society 6(1), 14-17 (2003)

18. Tatnall, A., Davey, B.: A New Spider on the Web: Modelling the Adoption of Web-Based Training. In: Nicholson, P., et al. (eds.) E-Training Practices for Professional Organizations, pp. 307-314. Kluwer Academic Publishers/IFIP, Assinippi Park (2005) 
19. Tatnall, A., Davey, B.: Information Systems Curriculum Using an Ecological Model. In: Khosrow-Pour, M. (ed.) Encyclopedia of Information Science and Technology, 2nd edn., pp. 1998-2003. Idea Group Reference, Hershey (2009)

20. Townsend, C.R., Harper, J.L., Begon, M.: Essentials of Ecology. Blackwell Science, Boston (2000)

21. Case, T.J.: An Illustrated Guide to Theoretical Ecology. Oxford University Press, New York (2000)

22. Krebs, C.J.: Ecology - The Experimental Analysis of Distribution and Abundance, 3rd edn. Benjamin Cummings, San Francisco (2001)

23. Tatnall, A.: Curriculum Cycles in the History of Information Systems in Australia. Heidelberg Press, Melbourne (2006)

24. Goodson, I.F.: School Subjects and Curriculum Change: Studies in Curriculum History - A Revised and Extended Edition. The Falmer Press, UK (1987)

25. Layton, D.: Science as General Education. Trends in Education (January 1972) 